\title{
The Challenge of Fostering Healthy Organizations: An Empirical Study on the Role of Workplace Relational Civility in Acceptance of Change and Well-Being
}

\author{
Annamaria Di Fabio ${ }^{1 *}$, Marco Giannini ${ }^{2}$, Yura Loscalzo ${ }^{2}$, Letizia Palazzeschi ${ }^{1}$, \\ Ornella Bucci ${ }^{1}$, Andrea Guazzini ${ }^{3}$ and Alessio Gori ${ }^{1}$
}

${ }^{1}$ Department of Education and Psychology (Psychology Section), University of Florence, Italy, ${ }^{2}$ Department of Health Science, University of Florence, Italy, ${ }^{3}$ Department of Education and Psychology (Psychology Section), Centre for the Study of Complex Dynamics, University of Florence, Florence, Italy

\section{OPEN ACCESS}

Edited by:

Radha R. Sharma,

Management Development Institute,

India

Reviewed by:

J. Goosby Goosby Smith,

Citadel, USA

Catherine S. Daus,

Southern Illinois University

Edwardsville, USA

*Correspondence:

Annamaria Di Fabio

adifabio@psico.unifi.it

Specialty section: This article was submitted to

Organizational Psychology,

a section of the journal

Frontiers in Psychology

Received: 30 May 2016 Accepted: 24 October 2016 Published: 21 November 2016

Citation:

Di Fabio A, Giannini M, Loscalzo Y, Palazzeschi L, Bucci O, Guazzini A and Gori $A$ (2016) The Challenge of Fostering Healthy Organizations: An

Empirical Study on the Role of

Workplace Relational Civility in

Acceptance of Change and

Well-Being. Front. Psychol. 7:1748.

doi: 10.3389/fpsyg.2016.01748
The world of work in the twenty-first century is characterized by globalization, instability, and unavoidable change. Organizations need to develop a positive relational environment in the workplace thereby enabling workers to enhance their personal resources in order to face with on-going changes in the sphere of work for promoting their well-being. Against this background, the aim of this research was to examine the relationship between workplace relational civility and both acceptance of change and well-being (hedonic well-being as well as eudaimonic well-being) beyond the effect of personality traits. The following instruments were administered to 261 Italian workers: the Ten Item Personality Inventory (TIPI), the Acceptance of Change Scale (ACS), the Satisfaction With Life Scale (SWLS), and the Meaningful Life Measure (MLM). The results of hierarchical regression analyses revealed that workplace relational civility explained a percentage of incremental variance beyond personality traits in relation to acceptance of change, life satisfaction, and meaning in life. These results underscore the positive relationship between workplace relational civility and acceptance of change, hedonic well-being, and eudaimonic wellbeing, offering new research and intervention opportunities to meet the challenge of fostering healthy organizations.

Keywords: positive healthy organizations, healthy business, workplace relational civility, acceptance of change, hedonic and eudaimonic well-being

\section{INTRODUCTION}

The world of work in the twenty-first century is characterized by globalization, instability, and unavoidable change (Savickas, 2011; Guichard, 2013). In this postmodern era, work and well-being play a key role in the health of individuals, and it is important to verify here the effect of a negative working place on the health and well-being of workers (Sparks et al., 2001; Arenas et al., 2015; Giorgi et al., 2015, 2016; Mucci et al., 2016). The insecurity of the current world of work highlights the need to promote "healthy organizations" from a primary prevention point of view (Hage et al., 2007; Kenny and Hage, 2009; Di Fabio and Kenny, 2015; Di Fabio and Gori, 2016b). The concept of healthy organizations is in line with the most recent definition of health of the World Health Organization (1998) that replaced the old definition that stated that health was simply the absence of disease. The most recent 
definition noted that "health is a state of complete physical, mental, spiritual and social well-being and not merely the absence of disease or infirmity" (World Health Organization, 1998). Starting from this definition, the World Health Organization (2007) underlined the importance for organizations of developing a culture of health in the world of work both for the well-being of workers and for the health of organizations starting from a primary prevention point of view.

A focus on healthy people and healthy organizations is introduced (Macik-Frey et al., 2007; World Health Organization, 2007). Healthy people deal with many challenges in the world of work and in general have satisfying and productive work and personal lives. Flourishing, resilience, and the ability to adapt themselves to environment, characterize healthy people. Starting from a point of view that initially characterized health as the absence of diseases (biomedical perspective), the concept of work has been broadening to examine positive work environment factors (humanistic perspective) for employee health, well-being and performance (Macik-Frey et al., 2007; Raya and Panneerselvam, 2013). Thus, attention to healthy people as flourishing and resilient workers is paid as well as the role of a positive work environment in promoting employee health, in terms of well-being and good performance within an organizational positive psychology perspective (Di Fabio, 2014a; Snyder et al., 2014; Di Fabio and Kenny, 2015; Di Fabio and Gori, 2016b). The positive psychology perspective (Seligman and Csikszentmihalyi, 2000; Seligman, 2002) is a recent framework characterized by emphasis on resources and on positive functioning rather than on negative functioning. This change of focus highlights the importance of gainful employment and life (Di Fabio, 2014a, 2015b; Snyder et al., 2014) for oneself and for the organization too, supporting one's own family, for a safe work environment, for job satisfaction, and for engagement with and creating a sense of belonging to the organization and healthy business. The following factors are essential in an organizational positive psychology framework: satisfaction with one's work, the development of talents and skills, and positive interpersonal relationships (Snyder et al., 2014; Di Fabio, 2014a). The value of such a framework (Seligman, 2002; Seligman and Csikszentmihalyi, 2000) is that it increases the quality of working life and organizational effectiveness and concentrates on the importance of enhancing individual resources (Boyatzis et al., 2002; Di Fabio, 2006, 2015a; Boyatzis and Saatcioglu, 2008; Boyatzis, 2009; Di Fabio and Kenny, 2012, 2015, 2016a,b; Di Fabio and Maree, 2012; Di Fabio and Palazzeschi, 2012a; Di Fabio et al., 2012, 2013; Sartori et al., 2013; Di Fabio and Saklofske, 2014a,b; Boyatzis et al., 2015; Di Fabio and Bucci, 2015 , 2016). The enhancement of individual resources impacts directly and indirectly on the professional life of individuals and the quality of work they produce. Furthermore, the quality of work seems to be associated with the quality of relationships in the workplace, highlighting the importance of such relationships in the overall life context (Blustein, 2011; Richardson, 2012). Positive organizational psychology thus underscores the need to develop positive and supportive relationships in the workplace (Blustein, 2011; Snyder et al., 2014; Di Fabio, 2015b).
The positive organizational psychology framework contains the idea of a healthy organization linked to the concept of "performance and health" (De Smet et al., 2007). Healthy organizations promote healthy business, relying on the importance of the health of individuals for organizational success in a framework characterized by a close connection between workers' well-being, organizational well-being and effective functioning (Di Fabio and Blustein, 2016a,b). A healthy organization can be defined as "one whose culture, climate and practices create an environment that promotes employee health and safety as well as organizational effectiveness" (Lowe, 2010; Ceschi et al., 2014). A healthy organization is conducive to healthy business, namely successful business (Grawitch and Ballard, 2016). Healthy business regards also the strong association between organizational profitability and workers' well-being (Raya and Panneerselvam, 2013; Arnoux-Nicolas et al., 2016). New ways of promoting good organizational relationships, including relationality (Blustein, 2011) and respectivity (Maree, 2012), can lead to healthy organizations (Di Fabio, 2014a, 2015b; Di Fabio and Kenny, 2016a). These relationships are fundamental aspects of people's lives with their focus on respect and care for oneself and for others (Di Fabio, 2014a, 2015b). This focus promotes flourishing relationships from a positive perspective and underscores the importance of a positive balance between "me," "us," "organization," "people," and "the world" (Snyder et al., 2014; Di Fabio, 2016a). This can be very useful in the construction of a new stage of social and human development marked by organizational and community maturity (Di Fabio, 2014a) characterized not simply by swinging between an egocentric position (centered on me) and an allocentric position (centered on others) but reaching a polycentric position (for mutually gain, for others and for myself) that asks for connectedness centered on reflexivity (Di Fabio, 2016a) and for the new paradigm of meaning (Di Fabio and Blustein, 2016a,b).

The following constructs are important in healthy organizations: prosocial organizational behavior (McNeely and Meglino, 1994), organizational citizenship behavior (Podsakoff et al., 1990), organizational support (Eisenberger et al., 1990), workplace civility (Di Fabio, 2015c), and workplace relational civility (WRC, Di Fabio and Gori, 2016b). This last construct refers to a new form of relational style in the workplace "characterized by respect and concern for oneself and others, interpersonal sensitivity, personal education, and kindness toward others. It also includes civil behaviors such as treating others with dignity and respecting social norms to facilitate peaceful and productive cohabitation" (Di Fabio and Gori, 2016b, p. 2). The workplace relational civility construct has three dimensions: Relational decency (RD) at work: decency-based relationships, characterized by respect for the self and others, assertiveness, ability to express convictions, and relational capacity; Relational culture $(\mathrm{RCu})$ at work: politeness, kindness, good education, courteousness; Relational readiness (RR) at work: sensibility toward others (speed in understanding the feelings of others and showing proactive sensibility), ability to read the emotions of others, concern for others, delicacy, attention to the reactions of others, empathy, and compassion. 
In particular, in comparison to the construct of emotional intelligence (EI), RR is a dimension of Workplace Relational Civility construct that refers to behavior in the workplace that is decent, prosocial, polite, careful, and that involves relational style patterns in line with one's involvement with others. RR in particular regards the understanding of the emotions of others quickly and easily, to demonstrate delicacy, empathy, compassion, and attention to their reactions. WRC thereby represents a larger construct that includes EI (Di Fabio and Gori, 2016b). Although, the academically accepted standard view of EI is as an ability model, we must acknowledge that there are other types of EI that are purported in the literature (Mayer et al., 2008; Stough et al., 2009). In the literature there are two main approaches to defining and measuring EI (Stough et al., 2009): EI as ability-based (Mayer and Salovey, 1997) and EI as trait-based self-report (Bar-On, 1997; Petrides and Furnham, 2000, 2001; Di Fabio et al., 2016).

The WRC can be assessed with a new "mirror" kind of measurement, the Workplace Relational Civility Scale (WRCS, Di Fabio and Gori, 2016b): the participants have to firstly describe their relationship with others, and then the relationship of others with them. This kind of measure allows a better evaluation of the interpersonal interactions helping to reduce bias and it recognizes the inconsistencies between how the person considers himself/herself during the interaction with others and how the person looks at others in their interaction with him/her. This kind of measurement enables individuals to reflect on his/her own actions and to examine the behavior of others, thereby making him/her more aware of the relational dynamics.

Organizations need to develop a positive relational environment in the workplace enabling workers to enhance their personal resources so that they can cope with the on-going changes in today's world of work and also improve their wellbeing (Di Fabio and Bernaud, 2008; Di Fabio and Palazzeschi, 2008, 2012b, 2015, 2016; Di Fabio, 2011, 2014a,b; Di Fabio et al., 2014; Snyder et al., 2014; Di Fabio and Gori, 2016a,b; Di Fabio and Kenny, 2016a,b).

In the present-day ever-changing and unstable world of work, acceptance of change is crucial (Di Fabio and Gori, 2016a). Acceptance of change (AC) is defined as "tendency to embrace rather than shy away from change." AC thus stems from the belief that, in their work and other activities, people who are able to accept change often find that the change has a positive impact on their working lives and their resource levels" (Di Fabio and Gori, 2016a, p. 2). Acceptance of change has the following dimensions: Predisposition to change: people's ability to learn from change and to use change to improve the quality of their lives; Support for change: social support perceived from others when the person is facing challenges; Change seeking: people's predisposition not only to seek change, but also to accept and integrate life and work changes; Positive reaction to change: experience of positive emotions able to predispose people to experience change positively and to benefit from it"; and Cognitive flexibility: the mental ability to go through between different concepts also adopting flexible cognitive processing strategies (Di Fabio and Gori, 2016a, p. 3).
From a positive psychology perspective and thus also from a healthy organizations perspective, promoting the well-being of workers is vital (Adkins, 1999; Danna and Griffin, 1999). In particular, from a positive psychology perspective (Seligman and Csikszentmihalyi, 2000; Seligman, 2002), it is possible to distinguish two forms of well-being: hedonic well-being and eudaimonic well-being. Hedonic well-being (Watson et al., 1988) has a cognitive component in terms of life satisfaction (Diener et al., 1985) and an affective component characterized by the ascendancy of positive emotions over negative emotions (Watson et al., 1988). Eudaimonic well-being concerns the full functioning of the person (Ryan and Deci, 2001) and relates to life meaning and purposefulness (Waterman et al., 2010; Gori et al., 2015). In previous research, important associations between positive relationships in the workplace, the tendency to accept changes, and both hedonic and eudaimonic well-being emerged (Di Fabio, 2014a, 2016a).

People who participate positively in the workplace, are generally able to communicate with others with kindness and to attune their expressions and behaviors to those of others to promote a climate of mutual respect, show also the tendency to accept change and respond easier to the current challenges of our society of complexity (Rehfuss and Di Fabio, 2012; Di Fabio, 2016a,b,c). Furthermore people can benefit from a work climate of decency, respect, and awareness between people, enhancing relational management (Di Fabio, 2015b), psychological strenghts (Di Fabio, 2014a; Di Fabio and Gori, 2016b), hedonic and eudaimonic wellbeing in terms respectively of life satisfaction, and flourishing, authenticity and life meaningfulness (Di Fabio, 2014a, 2016a,b). So, given the importance of the concepts of relationality and civility, the present study is related to the idea of promoting the acceptance of change and well-being at work, through relationality (Blustein, 2006; Di Fabio and Maree, 2012, 2016; Maree, 2013; Di Fabio, 2015b; Di Fabio and Gori, 2016a,b).

\section{Aim and Hypotheses}

The principal objective of this research was to assess the relationship among workplace relational civility, acceptance of change and well-being (hedonic well-being and eudaimonic well-being) controlling for the effects of personality traits.

The following three hypotheses were formulated.

H1: The workplace relational civility assessed by the WRCS will add a percentage of incremental variance beyond the variance explained by personality traits in relation to acceptance of change.

$\mathrm{H} 2$ : The workplace relational civility assessed by the WRCS will add a percentage of incremental variance beyond the variance explained by personality traits in relation to hedonic well-being (assessed by life satisfaction).

H3: The workplace relational civility assessed by the WRCS will add a percentage of incremental variance beyond the variance explained by personality traits in relation to eudaimonic well-being (assessed by meaning in life). 


\section{MATERIALS AND METHODS}

\section{Participants}

Two hundred and sixty-one Italian workers of different public and private organizations in central Italy participated in the study. The participants' ages ranged from 34 to 58 years $(M=$ $46.15, S D=8.642) .175$ workers $(67.00 \%)$ of the participants were men with a mean age of 46.85 years, $S D=8.582$ and $86(33.00 \%)$ were women with a mean age of $44.73, S D=8.638$.

\section{Measures}

\section{Personality Traits}

The 10 Item Personality Inventory (TIPI, Gosling et al., 2003), in the Italian version by Di Fabio et al. (2016) was used to evaluate personality traits. The questionnaire was developed on the basis of descriptors of the Big Five instruments. Each item consists of two separated attributes with response options on a 7-point Likert scale ranging from 1 (strongly disagree) to 7 (strongly agree). The TIPI identifies five personality dimensions: Extraversion (E) (example of item: "I see myself as extraverted, enthusiastic"), Agreeableness (A) (example of item: "I see myself as sympathetic, warm"), Conscientiousness (C) (example of item: "I see myself as dependable, self-disciplined"), Neuroticism (N) (example of item: "I see myself as calm, emotionally stable"), Openness (O) (example of item: "I see myself open to new experiences, complex"). The Italian version of the TIPI indicated good values of reliability $(E=0.82 ; A=0.78 ; C=0.79 ; N=0.71$; $O=0.74$; Di Fabio et al., 2016).

\section{Workplace Relational Civility}

The Workplace Relational Civility Scale (WRCS, Di Fabio and Gori, 2016b) was used to evaluate relational civility in the workplace. It is a self-report mirror instrument consisting of 26 items to assess relational civility at work. The WRCS has three dimensions: Relational readiness (RR) at work, Relational culture $(\mathrm{RCu})$ at work, and Relational decency $(\mathrm{RD})$ at work. The sum of these dimensions gives an overall score for workplace relational civility for each part of the WRCS (Part A and Part B) and a total score. Part A concerns the analysis of an individual's perception of himself or herself regarding a particular issue (example of item: "I was able to express my values and my beliefs calmly to others) while Part B concerns the analysis of an individual's perception of others regarding the same issue (example of item: "Others were able to express their values and their beliefs calmly to me"). The participants in the present study were asked to describe their general relationship with others over the past 3 months, and then to describe their perception of the general relationship of others with them over the same time period. The response format was a Likert scale with five responses $(1=$ not at all; $2=$ a little; 3 = somewhat; $4=$ much; $5=$ a great deal). The Cronbach's alphas for the three dimensions for Part A were: Factor 1A = Relational readiness $(\alpha=0.83)$; Factor $2 \mathrm{~A}=$ Relational culture $(\alpha=0.76)$; Factor $3 \mathrm{~A}=$ Relational decency $(\alpha=0.75)$. The factors for Part $\mathrm{B}$ were: Factor $1 \mathrm{~B}=$ Relational readiness $(\alpha=0.86)$; Factor $2 \mathrm{~B}=$ Relational culture $(\alpha=0.88)$; Factor $3 \mathrm{~B}=$ Relational decency $(\alpha$ $=0.85$ ). The Cronbach's alpha coefficients for the total score for Part A and Part B of the WRC were, respectively, $\alpha=0.87$ and $\alpha=0.92$.

\section{Acceptance of Change}

The Acceptance of Change Scale (ACS, Di Fabio and Gori, 2016a) was used in the present study to evaluate the tendency of the participants to accept or move toward change. The ACS has 20 items with response options on a 5-point Likert-type scale $(1=$ not at all, $2=$ a little, $3=$ somewhat, $4=$ much, $5=$ a great deal). The scale enables five dimensions to be distinguished: Positive reaction to change (example of item: "I am able to give new meanings to the things that I have been doing for a long time," Change seeking (example of item: "I am looking for changes in my life, even when things are going well," Cognitive flexibility (example of item: "If necessary, it is not difficult for me to change my mind," Predisposition to change (example of item: "Thinking about new plans is easy for me," and Support for change (example of item: "I trust the people close to me when faced with change").

The Cronbach's alpha coefficients for the five dimensions were $\alpha=0.83$ for Predisposition to change; $\alpha=0.79$ for Support for change; $\alpha=0.80$ for Change seeking; $\alpha=0.75$ for Positive reaction to change, $\alpha=0.72$ for Cognitive flexibility, and $\alpha=$ 0.88 for the overall scale.

\section{Life Satisfaction}

The Satisfaction With Life Scale (SWLS, Diener et al., 1985) in the Italian version by Di Fabio and Gori (2015) was used to evaluate life satisfaction as hedonic well-being. The scale consists of five items (examples of items: "I am satisfied with my life," "The conditions of my life are excellent") on a 7-point Likert scale ranging from $1=$ strongly disagree to $7=$ strongly agree. The scale has a one-dimensional factorial structure. The Cronbach's alpha coefficient was 0.85 .

\section{Meaning in Life}

The Italian version (Di Fabio, 2014c) of the Meaningful Life Measure (MLM, Morgan and Farsides, 2009) was utilized to assess meaning in life as eudaimonic well-being. The questionnaire consists of 23 items on a 7-point Likert scale ranging from $1=$ strongly disagree to $7=$ strongly agree. The MLM identifies five dimensions: Exciting life (e.g., "Life to me seems always exciting"), Accomplished life (e.g., "So far, I am pleased with what I have achieved in life"), Principled life (e.g., "I have a personal value system that makes my life worthwhile"), Purposeful life (e.g., "I have a clear idea of what my future goals and aims are"), Valued life (e.g., "My life is significant"). The Cronbach's alpha coefficients were 0.85 for Exciting life; 0.87 for Accomplished life; 0.86 for Principled life, 0.85 for Purposeful life; 0.84 for Valued life. The alpha value for the total score was 0.85 .

\section{Procedure and Data Analysis}

The administration procedure involved some trained research assistant psychologists who administered collectively the instruments to groups of workers in meeting room in their workplace.

The order of administration of the instruments was controlled to counterbalance the effects of the order of measures. Participants completed an informed consent form and the instruments were administered in line with the Italian Law (Law Decree DL-196/2003). The study adhered to the latest version of 
TABLE 1 | Means, standard deviations and correlations between TIPI, WRCS, ACS, SWLS, and MLM.

\begin{tabular}{|c|c|c|c|c|c|c|c|c|c|c|c|c|}
\hline & $M$ & $D S$ & 1 & 2 & 3 & 4 & 5 & 6 & 7 & 8 & 9 & 10 \\
\hline 1. Extraversion & 4.29 & 1.43 & - & & & & & & & & & \\
\hline 2. Agreeableness & 5.58 & 1.01 & $0.18^{\star \star}$ & - & & & & & & & & \\
\hline 3. Conscientiousness & 5.59 & 1.19 & $0.19^{\star \star}$ & $0.39^{\star \star}$ & - & & & & & & & \\
\hline 4. Emotional stability & 5.03 & 1.13 & $0.31^{\star *}$ & $0.47^{\star \star}$ & $0.40^{\star \star}$ & - & & & & & & \\
\hline 5. Openness & 4.91 & 1.09 & $0.30^{\star \star}$ & $0.26^{\star \star}$ & $0.24^{\star \star}$ & $0.31^{\star \star}$ & - & & & & & \\
\hline 6. WRCS Part A & 52.58 & 5.95 & 0.09 & $0.32^{\star \star}$ & $0.22^{\star \star}$ & $0.19^{\star \star}$ & $0.19^{\star \star}$ & - & & & & \\
\hline 7. WRCS Part B & 47.67 & 7.33 & $0.21^{\star \star}$ & $0.24^{\star \star}$ & $0.23^{\star \star}$ & $0.31^{\star *}$ & $0.21^{\star \star}$ & $0.40^{\star \star}$ & - & & & \\
\hline 8. ACS & 73.45 & 9.34 & $0.30^{\star \star}$ & $0.29^{\star \star}$ & $0.22^{\star \star}$ & $0.41^{\star \star}$ & $0.53^{\star \star}$ & $0.46^{\star \star}$ & $0.43^{\star \star}$ & - & & \\
\hline 9. SWLS & 25.04 & 5.73 & $0.27^{\star \star}$ & $0.32^{\star \star}$ & $0.25^{\star \star}$ & $0.37^{\star \star}$ & $0.27^{\star \star}$ & $0.32^{\star \star}$ & $0.46^{\star \star}$ & $0.40^{\star \star}$ & - & \\
\hline 10. MLM & 123.18 & 20.71 & $0.24^{\star \star}$ & $0.41^{* *}$ & $0.48^{\star \star}$ & $0.48^{\star \star}$ & $0.37^{\star *}$ & $0.39^{\star \star}$ & $0.50^{\star \star}$ & $0.42^{\star \star}$ & $0.41^{\star \star}$ & - \\
\hline
\end{tabular}

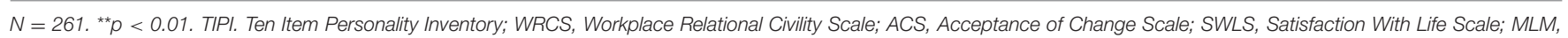
Meaningful Life Measure.

the Declaration of Helsinki revised in Fortaleza (World Medical Association [WMA], 2013) with regard to ethical standards for research. They were followed and approved by the Department of Education and Psychology of the University of Florence (Italy).

The participants were told that they could withdraw from the study at any time and that there would be no payment for participating. Firstly descriptive statistics and Pearson's $r$ correlations were carried out, and then hierarchical regressions were performed.

\section{RESULTS}

Means, standard deviations, and correlations between TIPI, WRCS, ACS, SWLS, and MLM are shown in Table $\mathbf{1 .}$

Regarding the differences between the gender groups and the age groups in respect to the three dependent variables, below there are the results of the generalized linear model analyses conducted adjusting for the unbalancing of gender factor within the sample, introducing such a factor as dummy variable. Moreover within the same models we considered the age as covariate variable.

The first model takes into account the ACS, reporting significant effects both for gender $F_{(1,257)}=6.538, p=0.05, \eta^{2}$ $=0.03$ and age $F_{(1,257)}=11.482, p=0.01, \eta^{2}=0.04$. For what concern the SWLS only the gender appears to play a significant effect $F_{(1,257)}=6.840, p=0.01, \eta^{2}=0.03$. The same happens for the MLM $F_{(1,257)}=5.733, p=0.05, \eta^{2}=0.02$. Despite their significance, all the previous effects appear to be characterized by a quite small magnitude in terms of effects dimensions, always ranging between 2 and $4 \%$ of the variance.

The results of three different hierarchical regression models are presented with acceptance of change, life satisfaction, and meaning in life as the criterion measures and with personality traits at the first step and workplace relational civility at the second step (Table 2).

As regard to acceptance of change, at the first step personality dimensions explained the $36 \%$ of the variance. At the second step, workplace relational civility added $12 \%$ of the
TABLE 2 | Hierarchical regression.

\begin{tabular}{llll}
\hline & ACS & SWLS & MLM \\
\hline & $\beta$ & $\beta$ & $\beta$ \\
\hline STEP 1 & & & \\
Extraversion & 0.08 & $0.10^{\star}$ & 0.01 \\
Agreeableness & 0.02 & $0.11^{\star}$ & $0.11^{\star}$ \\
Conscientiousness & 0.04 & 0.04 & $0.25^{\star \star \star}$ \\
Emotional stability & $0.20^{\star \star}$ & $0.14^{\star *}$ & $0.18^{\star \star}$ \\
Openness & $0.38^{\star \star \star}$ & 0.09 & $0.16^{\star \star}$ \\
STEP 2 & & & \\
WRCS Part A & $0.28^{\star \star \star}$ & $0.10^{\star}$ & $0.11^{\star}$ \\
WRCS Part B & $0.12^{\star}$ & $0.32^{\star \star \star}$ & $0.30^{\star \star \star}$ \\
$R^{2}$ step 1 & $0.36^{\star \star \star}$ & $0.20^{\star \star \star}$ & $0.38^{\star \star \star}$ \\
$\Delta R^{2}$ step 2 & $0.12^{\star \star \star}$ & $0.10^{* \star \star}$ & $0.10^{\star \star \star}$ \\
$R^{2}$ total & $0.48^{\star \star \star}$ & $0.30^{* \star \star}$ & $0.48^{\star \star \star}$ \\
\hline
\end{tabular}

The contributions of personality traits (first step) and workplace relational civility (second step) to acceptance of change (AC), life satisfaction (LS), meaning in life (ML).

$N=261 .{ }^{*} p<0.05 .{ }^{* \star} p<0.01 .{ }^{* \star *} p<0.001$. WRCS, Workplace Relational Civility Scale; ACS, Acceptance of Change Scale; SWLS, Satisfaction with Life Scale; MLM, Meaningful Life Measure.

When WRCS Part A and WRCS Part B were examined separately in Step 3 and Step 4, the models didn't account for a percentage greater of variance in relation to ACS, SWLS, and MLM.

incremental variance. The model overall accounted for $48 \%$ of the variance.

For what concerns the analysis explaining hedonic well-being as assessed by life satisfaction, at the first step personality traits accounted for $20 \%$ of the variance. At the second step, workplace relational civility added $10 \%$ of the incremental variance. The model overall accounted for $30 \%$ of the variance.

For what refers to the analysis explaining eudaimonic well-being as assessed by meaning in life, at the first step personality traits explained the $38 \%$ of the variance. At the second step, workplace relational civility added $10 \%$ of the incremental variance. The model overall accounted for $48 \%$ of the variance. 


\section{DISCUSSION}

The aim of this research was to investigate the role of workplace relational civility in acceptance of change and in both hedonic and eudaimonic well-being beyond the effects of personality traits.

The first hypothesis was confirmed as workplace relational civility added a percentage of incremental variance beyond the variance explained by personality traits in relation to acceptance of change. A relational style characterized by respect and concern for oneself and others, interpersonal sensitivity, personal education, and kindness toward others (Di Fabio and Gori, 2016b) was related to acceptance of change (Di Fabio and Gori, 2016a). These results highlight the importance of developing a positive workplace relational environment so that workers can enhance their psychological strenghts (Di Fabio, 2014a; Di Fabio and Gori, 2016b) useful not only for managing their relationships but also for welcoming the ongoing changes in the workplace (Di Fabio, 2014a; Snyder et al., 2014; Di Fabio and Kenny, 2016a,b; Di Fabio and Gori, 2016a,b). People characterized by workplace relational civility in the workplace, can face adequately critical issues of change and achieve their organizational objectives coping with changes (Di Fabio and Gori, 2016b). The tendency to accept changes based on a positive relationality can help people to react better and to deal successfully with the complexity of the twenty-first century world of work (Di Fabio, 2016a).

The second hypothesis was also confirmed as workplace relational civility added a percentage of incremental variance beyond the variance explained by personality traits in relation to hedonic well-being (assessed by life satisfaction). The results of the present study showed that perceptions of civility in relationships in the workplace in terms of treating others and being treating by others with dignity and with respect in the interests of peaceful and productive cohabitation (Di Fabio and Gori, 2016a) correlated positively with greater satisfaction with one's own life (Diener et al., 1985). Thus, a relational style characterized by respect and caring for the self and the others in the relationships between people can foster relational well-being in the workplace (Di Fabio and Gori, 2016b). The construction of a positive workplace climate can affect also the overall evaluation of a person's life, contributing to hedonic well-being of individuals in their workplace.

Finally, the third hypothesis was also confirmed as workplace relational civility added a percentage of incremental variance beyond the variance explained by personality traits in relation to eudaimonic well-being (assessed by meaning in life). These results thus also supported the positive relationship between workplace relational civility (Di Fabio and Gori, 2016b) and eudaimonic well-being in terms of optimal functioning (Morgan and Farsides, 2009). Thus the perception of relational civility in an organizational environment seems to contribute to the identification of one's own meaning in work, encouraging the pursuing of meaningful goals in line with authentic aspects of the Self. The perception of good relationships in the workplace can thereby contribute to the efforts for self-realization of workers, fostering healthy individuals for healthy business and healthy organizations.

It is interesting to note that the Part A of the Workplace Relational Civility Scale regarding the evaluation of the perception of the self in relationships with others was linked closely to acceptance of change, while Part B of the WRC Scale regarding the evaluation of the perception of the relationship of others with oneself was linked closely to both hedonic and eudaimonic well-being. It seems thus that the perception of one's own workplace relational civility tends to be associated with a willingness and a readiness to face change effectively, relying on a deeper reflection on one's own possible relational actions. The perception of others' workplace relational civility tends to be associated with life satisfaction and optimal functioning, underlying the value of the behaviors of others and of the relational dynamics in the construction of own well-being. The awareness of one's own behavior and of the behaviors of other people in social relationships in the workplace, can help individuals to manage more effectively the ever-changing and unpredictable demands of their workplace, also developing new relational skills to overcome difficulties and find better solutions for themselves and the organizations.

Notwithstanding the present study showed the relationships between workplace relational civility, acceptance of change and both hedonic and eudaimonic well-being, the following limitations of the study should be noted. The research was conducted with a group of Italian workers who were not representative of the Italian population. Future research should therefore include workers from different geographical areas in Italy, from different types of organizations, and also incorporate samples from other countries. Furthermore future research could examine workplace relational civility in relation to other aspects of hedonic well-being such as positive affect (Watson et al., 1988) or other aspects of eudaimonic well-being like the subjective experience of eudaimonia (Waterman et al., 2010), the existential fulfillment (Längle et al., 2003), and the flourishing (Diener et al., 2010).

Despite the limitations of the study, the findings do add to the literature on the contribution of workplace relational civility to acceptance of change and to hedonic and eudaimonic well-being.

If the results of the present study are confirmed by future research, new interventions could be introduced to enhance workplace relational civility and thereby promote "healthy organizations," particularly from a primary prevention perspective (Hage et al., 2007; Kenny and Hage, 2009; Di Fabio and Saklofske, 2014a; Di Fabio and Kenny, 2015). The endeavor of improving relational resources in the workplace could foster strengths of workers and organizations, important for increasing the tendency to accept the on-going changes in the world of work (Di Fabio, 2016a,b), to anticipate critical aspects and to early intervene to decrease possible risks (Hage et al., 2007; Kenny and Hage, 2009). Building a positive relational environment can also promote individual hedonic and eudaimonic wellbeing of workers in terms respectively of life satisfaction and meaning in life, strongly associated with organizational well-being. 
Conceptualizing organizational relationality in terms of workplace relational civility in a preventive positive framework could thus strengthen healthy organizations, underlining the importance of developing positive and supportive relationships in the workplace (Blustein, 2011; Di Fabio, 2014a, 2015b; Snyder et al., 2014; Di Fabio and Gori, 2016b) for a safer and more decent relational work environment (Di Fabio and Blustein, 2016a,b).

\section{REFERENCES}

Adkins, J. A. (1999). Promoting organizational health: the evolving practice of occupational health psychology. Prof. Psychol. Res. Pract. 30, 129-137. doi: 10.1037/0735-7028.30.2.129

Arenas, A., Giorgi, G., Montani, F., Mancuso, S., Perez, J. F., Mucci, N., et al. (2015). Workplace bullying in a sample of Italian and Spanish employees and its relationship with job satisfaction, and psychological well-being. Front. Psychol. 6:1912. doi: 10.3389/fpsyg.2015.01912

Arnoux-Nicolas, C., Sovet, L., Lhotellier, L., Di Fabio, A., and Bernaud, J.-L. (2016). Perceived work conditions and turnover intentions: the mediating role of meaning of life and meaning of work. Front. Psychol. 7:704. doi: 10.3389/fpsyg.2016.00704

Bar-On, R. (1997). The Emotional Intelligence Inventory (EQ-i): Technical manual. Toronto, ON: Multi-Health Systems.

Blustein, D. L. (2006). The Psychology of Working: A New Perspective for Career Development, Counseling and Public Policy. New York, NY: Routledge.

Blustein, D. L. (2011). A relational theory of working. J. Vocat. Behav. 79, 1-17. doi: 10.1016/j.jvb.2010.10.004

Boyatzis, R. E. (2009). Competencies as a behavioral approach to emotional intelligence. J. Manag. Develop. 28, 749-770. doi: 10.1108/02621710910987647

Boyatzis, R. E., Batista-Foguet, J. M., Fernández-i-Marín, X., and Truninger, M. (2015). EI competencies as a related but different characteristic than intelligence. Front. Psychol. 6:72. doi: 10.3389/fpsyg.2015.00072

Boyatzis, R. E., and Saatcioglu, A. (2008). A twenty-year view of trying to develop emotional, social and cognitive intelligence competencies in graduate management education. J. Manag. Develop. 27, 92-108. doi: $10.1108 / 02621710810840785$

Boyatzis, R. E., Stubbs, E. C., and Taylor, S. N. (2002). Learning cognitive and emotional intelligence competencies through graduate management education. Acad. Manag. Learn. Educ. 1, 150-162. doi: 10.5465/AMLE.2002. 8509345

Ceschi, A., Dorofeeva, K., and Sartori, R. (2014). Studying teamwork and team climate by using a business simulation: how communication and innovation can improve group learning and decision-making performance. Eur. J. Train. Dev. 38, 211-230. doi: 10.1108/EJTD-01-2013-0004

Danna, K., and Griffin, R. W. (1999). Health and well-being in the workplace: a review and synthesis of the literature. J. Manage., 25, 357-384. doi: 10.1177/014920639902500305

De Smet, A., Loch, M., and Schaninger, B. (2007). Anatomy of a Healthy Corporation. Mckinsey Q. 2, 1-11. Available online at: https://solutions. mckinsey.com/catalog/media/AnatomyOfAHealthyCorporation.pdf

Diener, E., and Emmons, R. A., Larsen, R. J., and Griffin, S. (1985). The satisfaction with life scale. J. Pers. Assess. 49, 71-75. doi: 10.1207/s15327752jpa4901_13

Diener, E., Wirtz, D., Tov, W., Kim-Prieto, C., Choi, D. W., Oishi, S., et al. (2010). New well-being measures: short scales to assess flourishing and positive and negative feelings. Soc. Indic. Res. 97, 143-156. doi: 10.1007/s11205-009-9493-y

Di Fabio, A. (2006). Decisional procrastination correlates: Personality traits, selfesteem or perception of cognitive failure? Int. J. Educ. Vocat. Guid. 6, 109-122. doi: 10.1007/s10775-006-9000-9

Di Fabio, A. (2011). Intelligence émotionnelle et résistance au changement: Quelques résultats empiriques [Emotional intelligence and resistance to change: some empirical results]. Rev. Psychol. Travail Organ. 17, 91-106. doi: $10.1016 /$ S1420-2530(16)30135-2

Di Fabio, A. (2014a). Career counseling and positive psychology in the 21st century: new constructs and measures for evaluating the effectiveness of intervention. J. Counsel. 1, 193-213.

\section{AUTHOR CONTRIBUTIONS}

ADF conceptualized the study, choose the theoretical framework, and chose measures. OB helped in the collection of the data. ADF, MG, YL, LP and OB analyzed the data and wrote the methods and results. Then all authors wrote the paper together and read and revised the manuscript several times.

Di Fabio, A. (2014b). Intrapreneurial self-capital: a new construct for the $21^{\text {st }}$ century. J. Employ. Counsel. 51, 98-111. doi: 10.1002/j.2161-1920.2014.00045.x

Di Fabio, A. (2014c). Meaningful life measure: primo contributo alla validazione della versione italiana [Meaningful life measure: first contribution to the validation of the Italian version]. Counsel. Giornale Italiano Ricerca Applic. 7, 307-315.

Di Fabio, A. (2015a). Beyond fluid intelligence and personality traits in social support: the role of ability-based emotional intelligence. Front. Psychol. 6:395. doi: 10.3389/fpsyg.2015.00395

Di Fabio, A. (2015b). Positive Relational Management Scale per Rilevare Positività e Complessità [Positive Relational Management Scale to Detect Positivity and Complexity]. Counseling. Giornale Italiano Ricerca Applic. 8. Available online at: http://rivistedigitali.erickson.it/counseling/archivio/vol-8-n-3/

Di Fabio, A. (2015c). Workplace Civility Scale: From Dark Side to Positive Side Nelle Organizzazioni [Workplace Civility Scale: From Dark Side to Positive Side in Organizations]. Counseling. Giornale Italiano di Ricerca e Applicazioni, 8. Available online at: http://rivistedigitali.erickson.it/counseling/ archivio/vol-8-n-2/

Di Fabio, A. (2016a). "The construction of personal project: the challenge of sustainability," in Career-Life Construction and Sustainability. Workshop at the World Conference of the UNESCO Chair "Lifelong Guidance and Counseling" in Wroclaw 2016, eds A. Di Fabio \& J. G. Maree (Moderators), D. L. Blustein (Discussant) (Wroclaw: University of Wroclaw (Poland)).

Di Fabio, A. (2016b). Positive Relational Management for Healthy Organizations: Psychometric Properties of a New Scale for Prevention for Workers. Front. Psychol. 7:1523. doi: 10.3389/fpsyg.2016.01523

Di Fabio, A. (2016c). Life design and career counseling innovative outcomes (CCIO): a case study. Career Dev. Q. 64, 35-48. doi: 10.1002/cdq.12039

Di Fabio, A., and Bernaud, J. (2008). The help-seeking in career counseling. J. Vocat. Behav., 72, 60-66. doi: 10.1016/j.jvb.2007.10.006

Di Fabio, A., Bernaud, J.-L., and Loarer, E. (2014). Emotional intelligence or personality in resistance to change? Empirical results in an Italian health care context. J. Employ. Counsel. 51, 146-157. doi: 10.1002/j.21611920.2014.00048.x

Di Fabio, A., and Blustein, D. L. (eds.) (2016a). Editorial ebook from meaning of working to meaningful lives: the challenges of expanding decent work. Front. Psychol. 7:1119 doi: 10.3389/fpsyg.2016.01119

Di Fabio, A., and Blustein, D. L. (eds.) (2016b). From Meaning of Working to Meaningful Lives: The Challenges of Expanding Decent Work. Lausanne: Frontiers Media. doi: 10.3389/978-2-88919-970-9 (Ebook)

Di Fabio, A., and Bucci, O. (2015). Affective profiles in Italian high school students: life satisfaction, psychological well-being, self-esteem, and optimism. Front. Psychol. 6:1310. doi: 10.3389/fpsyg.2015.01310

Di Fabio, A., and Bucci, O. (2016). Green positive guidance and green positive life counseling for decent work and decent lives: some empirical results. Front. Psychol. 7:261. doi: 10.3389/fpsyg.2016.00261

Di Fabio, A., and Gori, A. (2015). Measuring adolescent life satisfaction: psychometric properties of the Satisfaction With Life Scale in a sample of Italian adolescents and young adults. J. Psychoeduc. Assess. doi: $10.1177 / 0734282915621223$

Di Fabio, A., and Gori, A. (2016a). Developing a new instrument for assessing acceptance of change. Front. Psychol. 7: 802. doi: 10.3389/fpsyg.2016.00802

Di Fabio, A., and Gori, A. (2016b). Decent work and positive relational outcomes: Assessing Workplace Relational Civility (WRC) with a new multidimensional “mirror" measure. Front. Psychol. 7:890. doi: 10.3389/fpsyg.2016.00890

Di Fabio, A., Gori, A., and Giannini, M. (2016). Analizzare le Proprietà Psicometriche di Una Misura dei Big Five Con un Metodo Alternativo: L'esempio 
del Ten Item Personality Inventory (TIPI) [Analysing the Psychometric Properties of a Big Five Measurement Tool with an Alternative Method: The Example of the Ten Item Personality Inventory (TIPI)]. Counseling. Giornale Italiano di Ricerca e Applic. 9. doi: 10.14605/CS921618

Di Fabio, A., and Kenny, M. E. (2012). Emotional intelligence and perceived social support among Italian high school students. J. Career Dev. 39, 461-475. doi: $10.1177 / 0894845311421005$

Di Fabio, A., and Kenny, M. E. (2015). The contributions of emotional intelligence and social support to adaptive career progress among Italian youth. J. Career Dev. 42, 48-49. doi: 10.1177/0894845314533420

Di Fabio, A., and Kenny, M. E. (2016a). From decent work to decent lives: positive self and relational management (PS\&RM) in the twenty-first century. Front. Psychol. 7:361. doi: 10.3389/fpsyg.2016.00361

Di Fabio, A., and Kenny, M. E. (2016b). Promoting well-being: The contribution of emotional intelligence. Front. Psychol. 7:1182. doi: 10.3389/fpsyg.2016.01182

Di Fabio, A., and Maree, J. G. (2012). Group-based life design counseling in an Italian context. J. Vocat. Behav. 80, 100-107. doi: 10.1016/j.jvb.2011. 06.001

Di Fabio, A., and Maree, J. G. (2016). Using a transdisciplinary interpretive lens to broaden reflections on alleviating poverty and promoting decent work. Front. Psychol. 7:503. doi: 10.3389/fpsyg.2016.00503

Di Fabio, A., and Palazzeschi, L. (2008). Emotional intelligence and self-efficacy in a sample of Italian high school teachers. Soc. Behav. Pers. 36, 315-326. doi: 10.2224/sbp.2008.36.3.315

Di Fabio, A., and Palazzeschi, L. (2012a). Incremental variance of the core self-evaluation construct compared to fluid intelligence and personality traits in aspects of decision-making. Pers. Individ. Dif. 53, 196-201. doi: 10.1016/j.paid.2012.03.012

Di Fabio, A., and Palazzeschi, L. (2012b). Organizational justice: Personality traits or emotional intelligence? An empirical study in an Italian hospital context. J. Employ. Counsel. 49, 31-42. doi: 10.1002/j.2161-1920.2012.00004.x

Di Fabio, A., and Palazzeschi, L. (2015). Hedonic and eudaimonic well-being: the role of resilience beyond fluid intelligence and personality traits. Front. Psychol. 6:1367. doi: 10.3389/fpsyg.2015.01367

Di Fabio, A., and Palazzeschi, L. (2016). Marginalization and precariat: The challenge of intensifying life construction intervention. Front. Psychol. 7:444. doi: 10.3389/fpsyg.2016.00444

Di Fabio, A., Palazzeschi, L., Asulin-Peretz, L., and Gati, I. (2013). Career indecision versus indecisiveness: associations with personality traits and emotional intelligence. J. Career Assess. 21, 42-56. doi: $10.1177 / 1069072712454698$

Di Fabio, A., Palazzeschi, L., and Bar-On, R. (2012). The role of personality traits, core self-evaluation and emotional intelligence in career decisionmaking difficulties. J. Employ. Counsel. 49, 118-129. doi: 10.1002/j.21611920.2012.00012.x

Di Fabio, A., and Saklofske, D. H. (2014a). Promoting individual resources: the challenge of trait emotional intelligence. Pers. Individ. Dif. 65, 19-23. doi: 10.1016/j.paid.2014.01.026

Di Fabio, A., and Saklofske, D. H. (2014b). Comparing ability and self-report trait emotional intelligence, fluid intelligence, and personality traits in career decisions. Pers. Individ. Dif. 64, 174-178. doi: 10.1016/j.paid.2014.02.024

Di Fabio, A., Saklofske, D. H., and Tremblay,. P. F. (2016). Psychometric properties of the Italian trait emotional intelligence questionnaire (I-TEIQue). Pers. Indiv. Dif. 96, 198-201. doi: 10.1016/j.paid.2016.03.009

Eisenberger, R., Fasolo, P., and Davis-LaMastro, V. (1990). Perceived organizational support and employee diligence, commitment, and innovation. J. Appl. Psychol. 75, 51-59. doi: 10.1037/0021-9010.75.1.51

Giorgi, G., Mancuso, S., Fiz Perez, F., Castiello D’Antonio, A., Mucci, N., Cupelli, V., et al. (2016). Bullying among nurses and its relationship with burnout and organizational climate. Int. J. Nurs. Pract. 22, 160-168. doi: 10.1111/ijn.12376

Giorgi, G., Shoss, M. K., and Leon-Perez, J. M. (2015). Going beyond workplace stressors: Economic crisis and perceived employability in relation to psychological distress and job dissatisfaction. Int. J. Stress Manag. 22, 137. doi: $10.1037 / \mathrm{a} 0038900$

Gori, A., Craparo, G., Giannini, M., Loscalzo, Y., Caretti, V., La Barbera, D., et al. (2015). Development of a new measure for assessing insight: psychometric properties of the insight orientation scale (IOS). Schizophr. Res. 169, 298-302. doi: 10.1016/j.schres.2015.10.014
Gosling, S. D., Rentfrow, P. J., and Swann, W. B. Jr. (2003). A very brief measure of the Big Five personality domains. J. Res. Pers. 37, 504-528. doi: 10.1016/S00926566(03)00046-1

Grawitch, M. J., and Ballard, D. W. (2016). The Psychologically Healthy Workplace: Building a Win-Win Environment for Organizations and Employees. Washington, DC: American Psychological Association.

Guichard, J. (2013). "Career guidance, education, and dialogues for a fair and sustainable human development," in Inaugural Conference of the UNESCO Chair of Lifelong Guidance and Counselling (Wroclaw: University ofWroclaw).

Hage, S. M., Romano, J. L., Conyne, R. K., Kenny, M., Matthews, C., Schwartz, J. P., et al. (2007). Best practice guidelines on prevention practice, research, training, and social advocacy for psychologists. Couns. Psychol. 35, 493-566. doi: $10.1177 / 0011000006291411$

Kenny, M. E., and Hage, S. M. (2009). The next frontier: prevention as an instrument of social justice. J. Prim. Prev. 30, 1-10. doi: 10.1007/s10935-0080163-7

Längle, A., Orgler, C., and Kundi, M. (2003). The existence scale: a new approach to assess the ability to find personal meaning in life and to reach existential fulfillment. Euro. Psychother. 4, 135-146.

Lowe, G. (2010). Healthy Organizations: How Vibrant Workplaces Inspire Employees to Achieve Sustainable Success. Toronto, ON: University of Toronto Press.

Macik-Frey, M., Quick, J. C., and Nelson, D. L. (2007). Advances in occupational health: from a stressful beginning to a positive future. J. Manage. 33, 809-840. doi: $10.1177 / 0149206307307634$

Maree, J. G. (2012). Editorial. Promoting children's rights: rekindling respectivity. South Afr. J. Psychol. 42, 295-300. doi: 10.1177/008124631204200301

Maree, J. G. (2013). Counselling for Career Construction: Connecting Life Themes to Construct Life Portraits. Turning Pain into Hope. Rotterdam: Sense.

Mayer, J. D., Roberts, R. D., and Barsade, S. G. (2008). Human abilities: emotional intelligence. Ann. Rev. Psychol. 59, 507-536. doi: 10.1146/annurev. psych.59.103006.093646

Mayer, J. D., and Salovey, P. (1997). “What is emotional intelligence?," in Emotional Development and Emotional Intelligence: Educational Implications, eds P. Salovey and D. Sluyter (New York, NY: Basic Books), 3-31.

McNeely, B. L., and Meglino, B. M. (1994). The role of dispositional and situational antecedents in prosocial organizational behavior: an examination of the intended beneficiaries of prosocial behavior. J. Appl. Psychol. 79, 836-844. doi: 10.1037/0021-9010.79.6.836

Morgan, J., and Farsides, T. (2009). Measuring meaning in life. J. Happ. Stud. 10, 197-214. doi: 10.1007/s10902-007-9075-0

Mucci, N., Giorgi, G., Roncaioli, M., Perez, J. F., and Arcangeli, G. (2016). The correlation between stress and economic crisis: a systematic review. Neuropsychiatr. Dis. Treat. 12, 983-993. doi: 10.2147/NDT.S98525

Petrides, K. V., and Furnham, A. (2000). On the dimensional structure of emotional intelligence. Person. Individ. Differ. 29, 313-320. doi: 10.1016/S01918869(99)00195-6

Petrides, K. V., and Furnham, A. (2001). Trait emotional intelligence: psychometric investigation with reference to established trait taxonomies. Euro. J. Person. 15, 425-428. doi: 10.1002/per.416

Podsakoff, P. M., MacKenzie, S. B., Moorman, R. H., and Fetter, R. (1990). Transformational leader behaviors and their effects on followers' trust in leader, satisfaction, and organizational citizenship behaviors. Leadership Q. 1, 107-142. doi: 10.1016/1048-9843(90)90009-7

Raya, R. P., and Panneerselvam, S. (2013). The healthy organization construct: a review and research agenda. Indian J. Occupat. Environm. Med. 17, 89. doi: 10.4103/0019-5278.130835

Rehfuss, M., and Di Fabio, A. (2012). Validating the future career autobiography as a measure of narrative change. J. Career Assess. 20, 452-462. doi: 10.1177/1069 072712450005

Richardson, M. S. (2012). Counseling for work and relationship. Counsel. Psychol. 40, 190-242. doi: 10.1177/0011000011406452

Ryan, R. M., and Deci, E. L. (2001). "To be happy or to be self-fulfilled: a review of research on hedonic and eudaimonic well-being," in Annual Review of Psychology, Vol. 52, ed S. Fiske (Palo Alto, CA: Annual Reviews), 141-166.

Sartori, R., Favretto, G., and Ceschi, A. (2013). The relationships between innovation and human and psychological capital in organizations: a review. Innov. J. 18, 1-18. 
Savickas, M. L. (2011). Career Counseling. Washington, DC: American Psychological Association.

Seligman, M. E., and Csikszentmihalyi, M. (2000). Positive Psychology: An Introduction. Washington, DC: American Psychological Association.

Seligman, M. E. P. (2002). "Positive psychology, positive prevention, and positive therapy," in Handbook of Positive Psychology, eds C. R. Snyder and S. J. Lopez (New York, NY: Oxford University Press), 3-9.

Snyder, C. R., Lopez, S., and Teramoto Pedrotti, J. (2014). Positive Psychology: The Scientific and Practical Explorations of Human Strengths. London: Sage.

Sparks, K., Faragher, B., and Cooper, C. L. (2001). Well-being and occupational health in the 21st century workplace. J. Occupat. Organ. Psychol. 74, 489-509. doi: 10.1348/096317901167497

Stough, C., Saklofske, D., and Parker, J. (2009). Assessing Emotional Intelligence: Theory, Research, and Applications. New York, NY: Springer.

Waterman, A. S., Schwartz, S. J., Zamboanga, B. L., Ravert, R. D., Williams, M. K., Bede Agocha, V., et al. (2010). The questionnaire for eudaimonic well-being: psychometric properties, demographic comparisons, and evidence of validity. J. Posit. Psychol. 5, 41-61. doi: 10.1080/17439760903435208

Watson, D., Clark, L. A., and Tellegen, A. (1988). Development and validation of brief measures of positive and negative affect: the PANAS scales. J. Person. Soc. Psychol. 54, 1063-1070. doi: 10.1037/0022-3514.54.6.1063
World Health Organization (1998). World Health Organization Definition of Health. Available online at: http://www.who.ch/aboutwho/definition.htm

World Health Organization (2007). Workers' Health: Global Plan of Action. Sixtieth World Health Assembly. Available online at: http://www.who.int/ occupational_health/publications/global_plan/en/

World Medical Association [WMA] (2013). WMA Declaration of Helsinki-Ethical Principles for Medical Research Involving Human Subjects. Available online at : http://www.wma.net/en/30publications/10policies/b3/

Conflict of Interest Statement: The authors declare that the research was conducted in the absence of any commercial or financial relationships that could be construed as a potential conflict of interest.

Copyright (C) 2016 Di Fabio, Giannini, Loscalzo, Palazzeschi, Bucci, Guazzini and Gori. This is an open-access article distributed under the terms of the Creative Commons Attribution License (CC BY). The use, distribution or reproduction in other forums is permitted, provided the original author(s) or licensor are credited and that the original publication in this journal is cited, in accordance with accepted academic practice. No use, distribution or reproduction is permitted which does not comply with these terms. 